\title{
Induction Therapy in Half-Haplotype Low Risk Kidney Transplant Patients: Impact on Acute Rejection, Graft Survival, Infection and Surgical Complications at 3 Years
}

\author{
Maroun M. Abou-Jaoudé ${ }^{1,2,3, *}$, Ali H. Moussawi ${ }^{1,2}$, Eliane Younes ${ }^{3}$ \\ ${ }^{1}$ Transplantation Unit, The Middle East Institution of Health, Bsalim, Lebanon \\ ${ }^{2}$ Lebanese University, Faculty of Medical Sciences, Department of Surgery, Beirut, Lebanon \\ ${ }^{3}$ Nephrology \& Transplantation division, Sacré-Coeur Hospital, Brazilia-Baabda, Lebanon \\ *Corresponding author: marounaboujaoude@hotmail.com
}

Received June 14, 2019; Revised July 18, 2019; Accepted July 29, 2019

\begin{abstract}
Objective: This retrospective study discusses the need for induction therapy in half haplotype low immunological risk kidney transplant patients. Material and Methods: Records of 70 adult kidney transplant patients were reviewed with 3 years follow up. All patients were half haplotype matched with their living related donors and had PRA $<20 \%$ and DSA $0 \%$ when available. We divided the patients into 2 groups based on the induction therapy used during kidney transplantation. Hence, we compared 25 patients who were treated by induction therapy (anti-IL2 receptor antibodies or anti-Thymocyte globulin) (Group I) with 45 other patients who did not get any induction therapy (Group II). The primary endpoints comprised the rate and the severity of acute rejection episodes as well as the 3-year graft function and survival. Secondary endpoints contain: the frequency and the type of infections and the surgical complications at 1 year as well as the amount of malignancy and the patient survival at 1, 6, 12 and 36 months after kidney transplantation. Baseline demographic characteristics including: donor age, recipient and donor gender, cause of kidney disease, dialysis duration, donor to recipient CMV matching were similar in the two groups. Whereas, significant differences existed between the 2 groups in relation to: recipient age, pre-transplant hemoglobin blood level, anti-CMV prophylaxis regimen and maintenance immunosuppression. Results: We did not find any significant difference between the 2 groups regarding the length of hospital stay, the rate and severity of acute rejection, the rate of CMV infection, the occurrence of delayed graft function and the rate and type of surgical complications at 1 year. Furthermore, the patient and graft survival as well as the serum creatinine levels upon discharge and at 1, 3, 6, 12 and 36 months were also comparable. Nevertheless, the rate and type of out of Hospital infections and 1-year infection rate as well as the treatment cost were significantly higher in Group I. Conclusion: Induction therapy might not be desirable in low-immunological risk half-haplotype kidney transplant patients.
\end{abstract}

Keywords: kidney, transplantation, induction therapy

Cite This Article: Maroun M. Abou-Jaoudé, Ali H. Moussawi, and Eliane Younes, "Induction Therapy in Half-Haplotype Low Risk Kidney Transplant Patients: Impact on Acute Rejection, Graft Survival, Infection and Surgical Complications at 3 Years." American Journal of Medical Sciences and Medicine, vol. 7, no. 2 (2019): 44-53. doi: 10.12691/ajmsm-7-2-5.

\section{Introduction}

Since its first successful attempt in 1954, kidney transplantation (KT) has witnessed tremendous progression in graft survival (GS), as well as acute rejection (AR) rate and severity. This excellent success would not be achieved without the improvement of immunosuppression drugs and the continuous emergence of new and more selective regimens [1]. This has resulted in AR rate of $80 \%$ and 1 -year GS of $45 \%$ in the early 60 's to less than $15 \%$ and more than $90 \%$ respectively in the late 2000 [2].
Part of this improvement is related to the introduction of induction therapy as an essential part of the immunosuppression protocols by the administration of either monoclonal or polyclonal antibodies. Their use in kidney transplant recipients (KTRs) was aiming mainly to avoid early AR historically known to predict graft loss [3], in patients suffering from delayed graft function (DGF) [4] and in many immunosuppression protocols used to avoid or to minimize calcineurin inhibitors (CNIs) [5] based immunosuppression therapy. Therefore, induction therapy is widely used in KT to improve both short- and long-term graft outcomes. In USA, $82 \%$ of all KTRs receive induction therapy, with $46 \%$ given T-cell-depleting 
agents and approximately $22 \%$ given a non-depleting interleukin-2 receptor antagonist (IL-2RA) [6].

Presently, the choice of induction therapy is mandatory in respect to the risk-benefit evaluation for each patient. According to the latest KDIGO guidelines [1], KTRs who should receive depleting antibodies based induction therapy are those who are at high immunological risk to develop AR (recipients with high number of Human Leucocyte Antigens (HLA) mismatch with their donors or with high panel reactive antibody (PRA)). The remaining patients, considered at low immunological risk, are candidate for IL2-RA based induction therapy administration. However, the degree of HLA mismatch between donors and recipients in addition to the threshold of PRA rate are not well defined in KDIGO-guidelines. Therefore, induction therapy should be used in all types of HLA mismatches. In current practice, all low immunological risk half-haplotype patients (except for the fully matched HLA patients) are systematically given induction immunosuppression therapy.

But the routine use of induction therapy which target receptors located on the lymphocytes membranes can be related to a substantial risk of acute and late-onset adverse events; therefore, clinical risk-versus benefit ratio must be carefully balanced in every patient [7]. Some of these side effects are immediate, like the acute reaction secondary to the cytokines release syndrome [8-11] and others are delayed like the development of blocking antibodies and serum sickness [12]. Moreover, increased incidence of viral infections, mainly Cytomegalovirus (CMV) and malignancies (lymphoproliferative disease) have been reported in patients mainly treated with lymphocytedepleting induction [13-16]. To these major side effects, the use of induction therapy will significantly increase the overall fees of the transplantation surgery. Consequently, these facts have induced changes in the medical behavior toward trying to identify a category of patients where induction therapy can be spared.

The aim of our study is to evaluate the necessity of induction therapy in this category of low immunological risk, half-haplotype KTRs.

The primary endpoints comprised the rate and the severity of AR episodes as well as the 1 and 3-year graft function and survival in addition to the cost burden of the induction regimen. Secondary endpoints contain: the frequency and the type of infections and the surgical complications at 1 year as well as the amount of malignancy and the patient survival (PS) at 1, 6, 12 and 36 months after $\mathrm{KT}$.

\section{Material and Methods}

Patients and Donors. This is a retrospective study of the medical files of 70 adult kidney transplant patients (55 males and 15 females; mean age $34.23 \pm 11.29$ years; range 16 to 60 years) operated from September 1998 till December 2014 with a follow-up of 3 years. All patients were Caucasians. Inclusion criteria comprised all first KTRs considered at low immunological risk as defined by a PRA less to $20 \%$ and/or undetectable donor specific antibodies (DSA) when available. All recipients had halfhaplotype living donors (28 males and 42 females; mean age of $39.09 \pm 12.20$ years and range: $19-62$ years). Fifty five patients received a kidney from identical blood group donors. The cause of end stage renal disease was unknown in 31 patients (Table 1). The duration of dialysis before KT ranged from 0 to 108 months (mean of $11.18 \pm 18.23$ months). Twelve patients had a preemptive KT.

Surgical Procedure. All allografts were implanted in the iliac fossa. Vascular anastomoses were done on the recipient external iliac vessels in an end-to-side fashion. Vesico-ureteral anastomosis was performed as described by Shanfield [17]. An internal double-J ureteric stent was inserted routinely to lessen urological complications and then removed after 6 weeks by cystoscopy [18]. The operative field was drained routinely by a closed catheter. Foley catheters were removed on day 3 after KT and urine culture was routinely done.

Table 1. End stage renal disease etiology

\begin{tabular}{|l|c|c|c|}
\hline & $\begin{array}{c}\text { ALL patients } \\
(\mathbf{n}=\mathbf{7 0})\end{array}$ & $\begin{array}{c}\text { Induction Group } \\
(\mathbf{n}=\mathbf{2 5}) \text { Group I }\end{array}$ & $\begin{array}{c}\text { No Induction Group (n= 45); } \\
\text { Group II }\end{array}$ \\
\hline Unknown etiology & 31 & 9 & 22 \\
\hline Chronic glomerulonephritis & 9 & 4 & 5 \\
\hline Chronic pyelonephritis & 6 & 1 & 1 \\
\hline Polycystic kidney disease & 2 & - & 2 \\
\hline Lupus nephritis & 2 & 4 & 3 \\
\hline FSGS & 7 & - & 2 \\
\hline Arterial hypertension & 2 & 1 & - \\
\hline Berger disease & 1 & 3 & - \\
\hline Interstitial nephritis & 3 & 1 & - \\
\hline Diabetic nephropathy & 1 & - & 2 \\
\hline Alport disease & 2 & 1 & 1 \\
\hline Amyloidosis & 2 & - & 2 \\
\hline Renal hypoplasia & 2 & 1 & \\
\hline
\end{tabular}

Abbreviation: FSGS = Focal segmental glomerulosclerosis. 
Perioperative Antibiotic Prophylaxis. First-generation Cephalosporins were routinely given pre-operatively and continued for 24 hours thereafter. CMV prophylaxis was done by the administration of intravenous Ganciclovir whose dose was adjusted according to the estimated glomerular filtration rate (eGFR). This CMV prophylaxis was extended by the use of oral Valacyclovir or lately Valganciclovir for a period of 3 months or for 6 months in patients at high risk to develop CMV infection (the use of anti-thymocyte globulin-Fresenius (ATG-F) extended protocol, multiple AR episodes needing high dose of steroids, or CMV-negative recipient receiving a kidney from a CMV-positive donor). Furthermore, KTRs received Trimethoprim/Sulfamethoxazole for 1 year after KT to prevent Pneumocystis carinii infection.

Immunosuppressive regimen: Twenty five patients (Group I) received induction therapy during surgery either ATG-F bolus at a dose of $6 \mathrm{mg} / \mathrm{kg}$ (13 patients) or anti-IL2-RA (12 patients). The remaining 45 patients did not receive any induction (Group II). In addition, $500 \mathrm{mg}$ Methylprednisolone was administered intravenously during surgery than tapered progressively to $0.2 \mathrm{mg} / \mathrm{kg} /$ day of Prednisone over the next month. Maintenance immunosuppression consisted in either Cyclosporine microemulsion (CyA-me) started right after the transplant a dose of $5 \mathrm{mg} / \mathrm{kg}$ twice daily or Tacrolimus (Tacro) at a dose of $0.1 \mathrm{mg} / \mathrm{kg}$ twice daily. In case of slow graft function (SGF) or DGF occurrence, CNIs were postponed for few days. Mycophenolate mofetil (MMF) was started 48 hours before KT at $1 \mathrm{gm}$ twice a day than reduced to $750 \mathrm{mg}$ twice daily in Tacro patients.

Diagnosis of infections. Preoperatively, routine cultures of urine, throat, nose, peritoneal fluid (in peritoneal dialysis patients), and blood (in case of hemodialysis catheter) were done. In addition, CMV, Epstein-Barr virus (EBV), Herpes simplex virus (HSV), Herpes zoster, and Toxoplasmosis serology was also implemented. KT was postponed in case of active infection. Post-operative infections were diagnosed based on blood, urine and sputum cultures. Routine cultures of all indwelling arterial and central venous catheters were done after their removal including hemodialysis and peritoneal dialysis catheters. Intravascular catheters were considered infected, if more than 15 organisms were cultured from their tip, using the Maki technique [19], regardless if fever was present or whether blood cultures were positive. Urinary infection was detected if more than 100000 organisms $/ \mathrm{ml}$ were cultured. Viral infections were diagnosed on the basis of polymerase chain reaction (PCR) in blood, urine or tissue specimen, or histological proof of tissue invasion. In case of CMV disease or syndrome, CMV testing was performed. BK virus infection was suspected in case of occurrence of symptoms, or a rise in serum creatinine level. Therefore, kidney graft biopsy and blood BK-PCR tests were performed for diagnosis and specific immunohistochemistry coloration was done systematically. All infections occurring during the first year after KT were recorded.

Diagnosis of rejection. AR was diagnosed by kidney graft biopsy using the Banff classification for histological confirmation [20]. A 3-day course of bolus steroids was given for treatment and additional ATG-F was administered for steroid-resistant cases.
Statistical analysis. Data analysis was conducted using SPSS for windows v.13. They were expressed as percentages of total (categorical variables) or as mean SD (continuous variables). The differences in means were studied using Student's t-test, and the inter-group significance was done by Pearson

tests. $\mathrm{P}<0.05$ was settled as the threshold for statistical significance.

\section{Results}

The studied patients were allocated into either those who received induction therapy (Group I; $\mathrm{n}=25$ ) or those who did not (Group II; $n=45$ ). In group I, induction therapy consisted of IL2-RA (13 patients), or intraoperative bolus of ATG-F (12 patients). The demographics of donors and recipients are shown in Table 2. Older recipients were observed in Group I (mean age: $39.7 \pm$ 10.5 ) in contrast to Group II (mean age: $31.1 \pm 10.6$ ). But, the donor age was similar in both groups (mean age: 39.8 \pm 12.3 and $38.6 \pm 12.2$ respectively; $p$ value $=$ N.S.). Despite the predominance of female recipients in both groups and more female donors in Group II, this was not statistically significant. Maintenance immunosuppression comprised triple therapy in which Neoral $(\mathrm{N})$, Tacrolimus (Tacro), or Sirolimus was combined with an antimetabolite [MMF or Azathioprine (A)] and Prednisone (P). One patient in Group II but none in Group I received quadruple therapy (Tacro, Sirolimus, MMF and Prednisone) (Table 3).

Table 2. Patient's and donor's demographics

\begin{tabular}{|l|c|c|c|}
\hline & $\begin{array}{c}\text { Group I } \\
(\mathrm{n}=25)\end{array}$ & $\begin{array}{c}\text { Group II } \\
(\mathrm{n}=45)\end{array}$ & P value \\
\hline Recipient age (years) & $39.7 \pm 10.3$ & $31.1 \pm 10.6$ & 0.002 \\
\hline Recipient gender (M/F) & $20 / 5$ & $35 / 10$ & N.S. \\
\hline Donor age (years) & $39.8 \pm 12.3$ & $38.6 \pm 12.2$ & N.S. \\
\hline Donor gender (M/F) & $13 / 12$ & $15 / 30$ & N.S. \\
\hline $\begin{array}{l}\text { Donor/Recipient blood group } \\
\text { Identical }\end{array}$ & 22 & 33 & N.S \\
Compatible & 3 & 12 & \\
\hline Pre-transplant dialysis (months) & $13.5 \pm 19.1$ & $9.8 \pm 17.7$ & N.S. \\
\hline Preemptive (patients) & 4 & 8 & N.S. \\
\hline
\end{tabular}

Abbreviations: $\mathrm{M}=$ Male; $\mathrm{F}=$ Female.

Table 3. Maintenance Immunosuppression medication

\begin{tabular}{|c|c|c|}
\cline { 2 - 3 } \multicolumn{1}{c|}{} & Group I $(\mathrm{n}=25)$ & Group II $(\mathrm{n}=45)$ \\
\hline NAP & 1 & 3 \\
\hline NCP & 15 & 14 \\
\hline FCP & 7 & 17 \\
\hline N/FCP & 1 & 6 \\
\hline N/RCP & 1 & 1 \\
\hline FRCP & 0 & 1 \\
\hline F/NCP & 0 & 3 \\
\hline
\end{tabular}

Abbreviations: N: Neoral; F: Tacrolimus; A: Azathioprine; R: Rapamune; C: MMF; P: Prednisone; $P$ value $=0.034$. 
Hematologic profiles. The pre-transplant hemoglobin blood levels and the difference between pre and post renal transplant hemoglobin blood levels were statistically different between the 2 groups, without any impact on the need of post-transplant PRBC transfusions (3 patients in group I and 14 patients in Group II). Moreover, the difference between the pre and the post-transplant platelets blood levels was significantly higher in Group I $(\mathrm{P}$ value $=0.006)$ despite the similarity of pre and post-transplant platelets blood levels between the 2 groups (Table 4).

Acute Rejection. Overall, 7 patients (10\%) developed AR between day 3 and day 121 after KT: 2 patients in Group I (8\%) and 3 others in Group II (11.1\%) (P value = N.S.). All were reversible after appropriate treatment. However, in 2 patients in Group II, ATG-F was needed to reverse steroid-resistant AR but none in Group I (P value = N.S.).

Infection. A total of 32 infections were identified in 25 out of 70 patients $(35.7 \%)$ during the 1-year follow-up period. They were divided into bacterial $(n=20 ; 62.5 \%)$, viral $(n=9 ; 28.1 \%)$ and fungal infections $(n=3 ; 9.4 \%)$. More infected patients were found in Group I (56\%) than in Group II $(24.4 \%)$ up to 1 year after KT (P value $=$ $0.005)$. The same was found regarding the number of infectious episodes, which was statistically higher in Group I $(\mathrm{n}=17)$ than in group II $(\mathrm{n}=15)(\mathrm{P}$ value $=$ $0.033)$. Most of the infections were bacterial being most frequent in Group I $(n=12 ; 70.5 \%)$ than in Group II $(n=8$;
$53.3 \%)(\mathrm{P}$ value $=0.025)$. They were followed by viral infections: 4 infections and 5 others in Group I and Group II respectively. Fungal infections were detected in 1 patient in Group I and in 2 patients in Group II. (Figure 1).

The in-hospital infections (which occur during the patient's hospital stay following KT), rate was comparable between the 2 groups: $8(32 \%)$ and $9(20 \%)$ infected patients in Group I and Group II respectively. Eight infectious episodes (all bacterial) were detected in group I and 12 others in group II distributed as follows: 8 bacterial, 3 viral and 1 fungal (Figure 2).

Comparatively, the "Out of hospital infections" (from the patient's discharge from the hospital till 1 year after KT) rate was greater in Group I (7 patients; $28 \%$ ) than in Group II (3 patients; 6.7\%) $(\mathrm{P}$ value $=0.011)$. The total number of infectious episodes and the rate of bacterial infections were statistically different between the 2 groups ( $\mathrm{P}$ value $=0.006$ and 0.004 respectively) as shown in Figure 3 .

Concerning CMV infections, despite the similar CMV donor and recipient status, CMV prophylaxis was more commonly done in Group I (76\%) than in Group II $(33 \%)(\mathrm{P}$ value $=0.007)$ using either Valaciclovir or Valganciclovir. But this did not have any effect on the occurrence of CMV disease $(\mathrm{P}$ value $=$ N.S. $)$. All cases of CMV disease were gastro-intestinal. Three (12\%) were detected in Group I on day 92, 125 and 194 after KT and 2 diagnosed in Group II on day 76 and 180 after KT (Table 5).

Table 4. Hematologic profile

\begin{tabular}{|l|c|c|}
\cline { 2 - 3 } \multicolumn{1}{c|}{} & Group I (n=25) & Group II (n=45) \\
\hline Pre-Tx Hb blood level $(\mathrm{gm} / \mathrm{dl})$ & $10.1 \pm 1.2$ & $9.0 \pm 2.0$ \\
\hline Post-Tx Hb blood level $(\mathrm{gm} / \mathrm{dl})$ & $7.0 \pm 1.5$ & $7.7 \pm 1.6$ \\
\hline Drop in Hb blood level $(\mathrm{gm} / \mathrm{dl})$ & $3.1 \pm 1.3$ & $1.7 \pm 1.5$ \\
\hline Needs for Post-Tx transfusions & 8 units (5 patients) & 14 units (9 patients) \\
\hline Pre-Tx Plat blood level & $238360 \pm 89078.5$ & $206133.3 \pm 82217.7$ \\
\hline Post-Tx Plat blood level & $130960 \pm 75832.8$ & $156911.1 \pm 52379.6$ \\
\hline Drop in Plat blood level & $107240 \pm 61090.2$ & N.S. \\
\hline
\end{tabular}

Abbreviation: $\mathrm{Hb}=$ hemoglobin; $\mathrm{Tx}=$ Transplant; Plat $=$ Platelets.

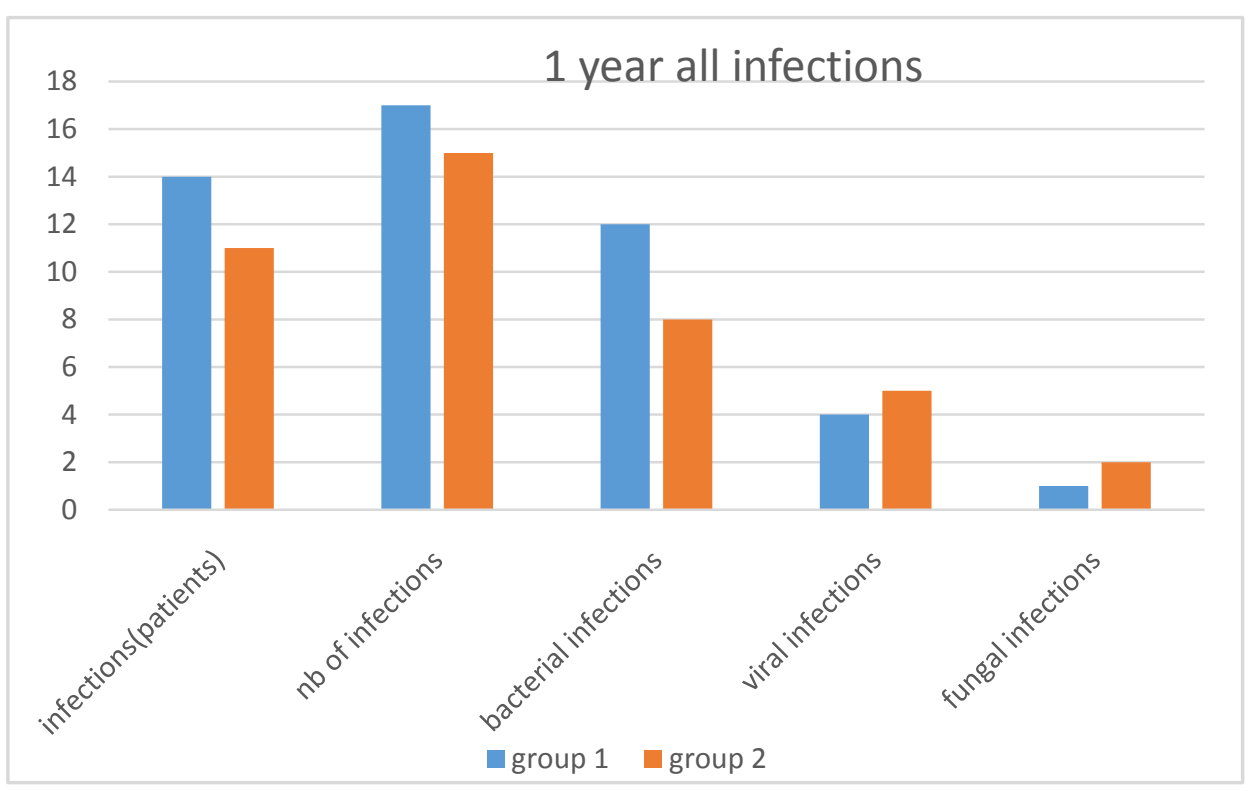

Figure 1. Rate and type of all infections at 1 year 


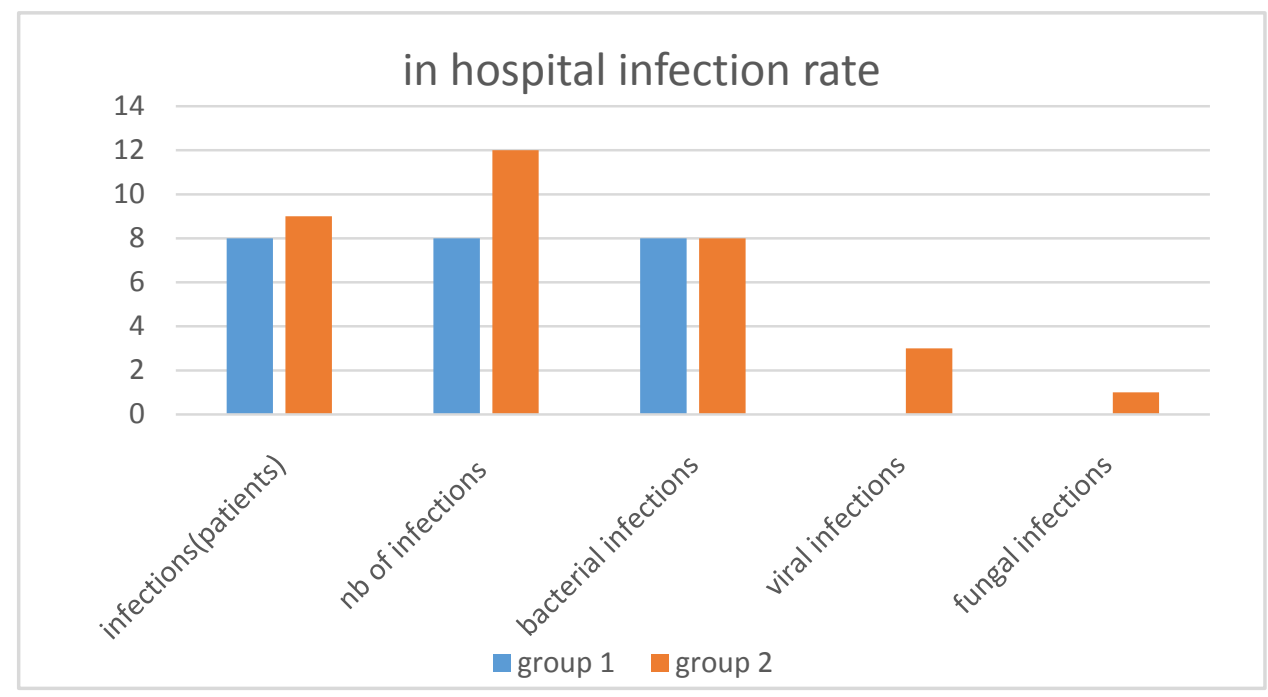

Figure 2. Rate and type of In-hospital infections

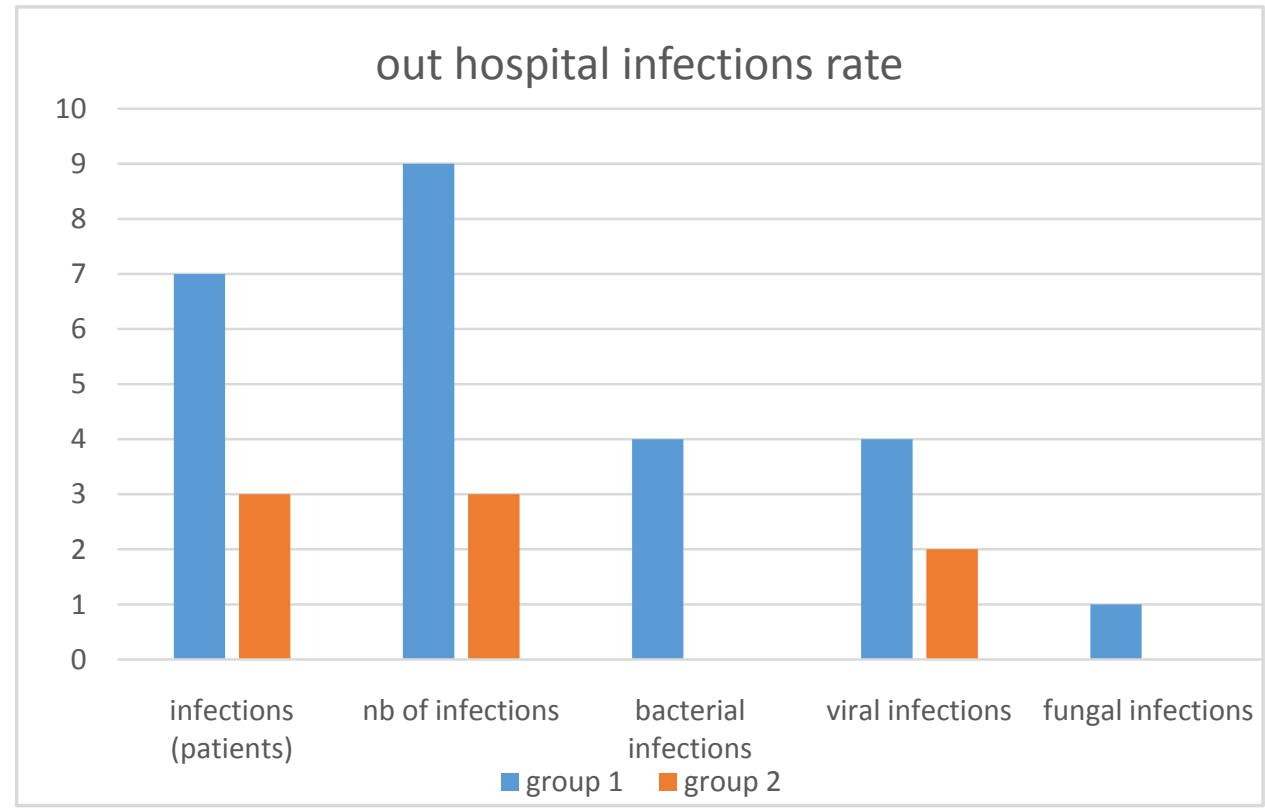

Figure 3. Rate and type of Out of hospital infections

Table 5. CMV status in donors and KTRs

\begin{tabular}{|l|c|c|c|}
\cline { 2 - 4 } \multicolumn{1}{c|}{} & $\begin{array}{c}\text { Group I } \\
(\mathrm{n}=25)\end{array}$ & $\begin{array}{c}\text { Group II } \\
(\mathrm{n}=45)\end{array}$ & P value \\
\hline Donor-to-recipient status & & & \\
N/P & 0 & 1 & \\
P/N & 2 & 2 & N.S. \\
P/P & 6 & 1 & \\
\hline CMV prophylaxis & 17 & 41 & \\
None & $6(24 \%)$ & $30(67 \%)$ & \multirow{2}{*}{0.007} \\
Valaciclovir & $12(48 \%)$ & $7(15 \%)$ & \\
Valganciclovir & $7(28 \%)$ & $8(18 \%)$ & \\
\hline CMV infection & $3(12 \%)$ & $2(4.4 \%)$ & \multirow{2}{*}{ N.S. } \\
CMV disease & GI $=3$ & GI $=2$ & \\
CMV type & $92,125,194$ & 76,180 & \\
CMV timing (days) & & & \\
\hline
\end{tabular}

Abbreviations: $\mathrm{N}=\operatorname{IgG}(-) ; \mathrm{P}=\operatorname{IgG}(+)$.
Patient's outcome and graft function. There were no differences between the 2 groups regarding the length of patient's hospital stay and the rate of DGF occurrence. Graft function, represented by serum creatinine level, didn't show any significant difference between the 2 groups $(\mathrm{P}$ value $=$ N.S. $)($ Table 6$)$.

Table 6. Patient's outcome and graft function

\begin{tabular}{|l|c|c|c|}
\cline { 2 - 4 } \multicolumn{1}{c|}{} & $\begin{array}{c}\text { Group I } \\
(\mathrm{n}=25)\end{array}$ & $\begin{array}{c}\text { Group II } \\
(\mathrm{n}=45)\end{array}$ & P value \\
\hline Hospital stay (days) & $\begin{array}{c}11.3 \pm 1.9 \\
(9-16)\end{array}$ & $\begin{array}{c}10.4 \pm 5.8 \\
(6-41)\end{array}$ & N.S. \\
\hline DGF & $0(0 \%)$ & $2(4.4 \%)$ & N.S. \\
\hline Serum creatinine $(\mathrm{mg} / \mathrm{dl})$ & & & \\
Upon discharge & $1.3 \pm 0.4$ & $1.3 \pm 0.6$ & \\
1 month & $1.3 \pm 0.3$ & $1.4 \pm 0.5$ & \\
3 months & $1.2 \pm 0.2$ & $1.4 \pm 0.6$ & N.S. \\
6 months & $1.2 \pm 0.2$ & $1.4 \pm 0.6$ & \\
1 year & $1.2 \pm 0.2$ & $1.3 \pm 0.6$ & \\
3 years & $1.21 \pm 0.24$ & $1.26 \pm 0.69$ & \\
\hline
\end{tabular}

Abbreviation: $\mathrm{DGF}=$ delayed graft function. 


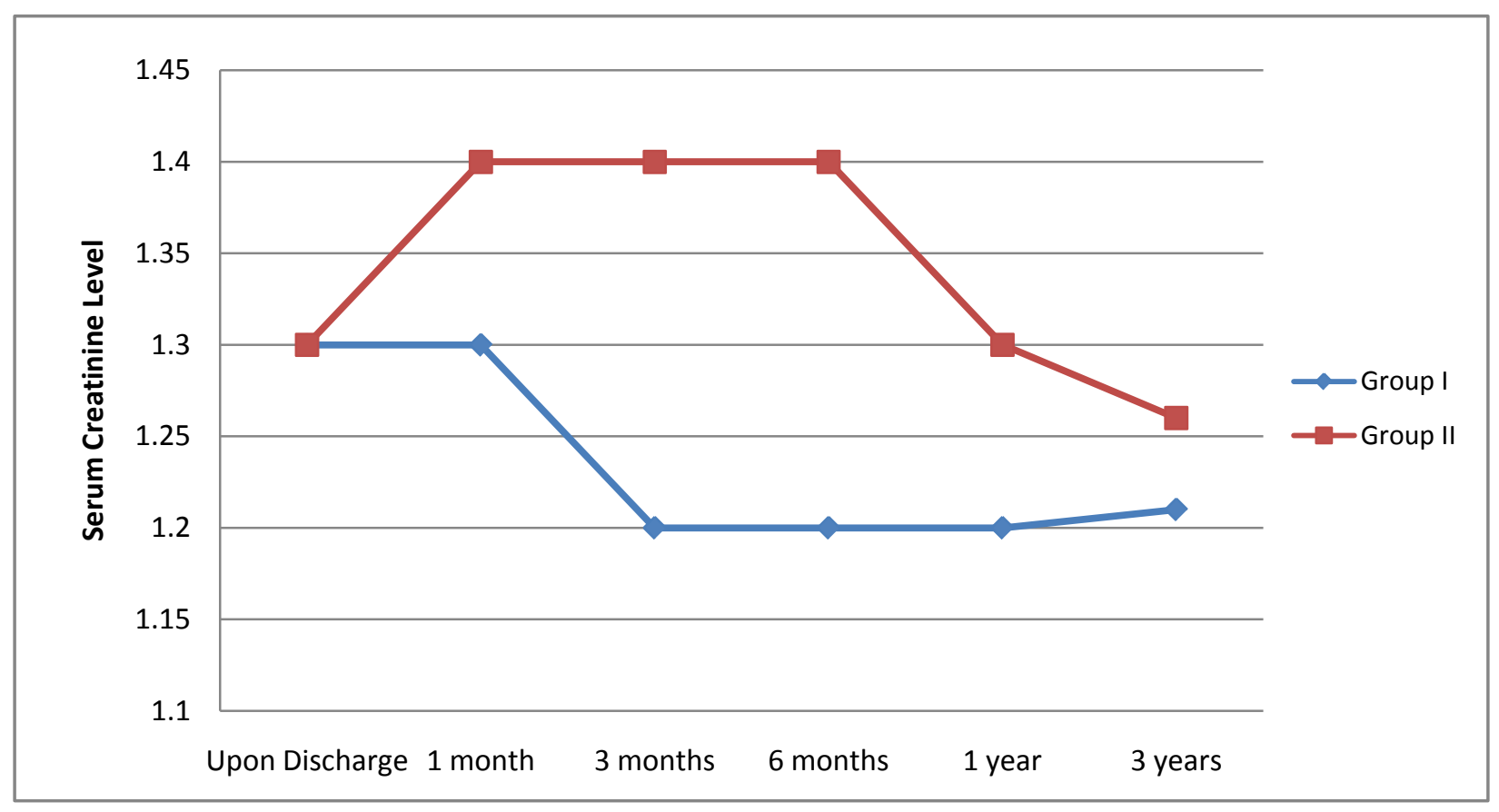

Figure 4. Serum creatinine level $(\mathrm{mg} / \mathrm{dl})$ upon discharge and till 3 years after KT

Table 7. GS and PS at 1 and 3 years

\begin{tabular}{|l|c|c|c|}
\hline & $\begin{array}{c}\text { Group I } \\
(\mathrm{n}=25)\end{array}$ & $\begin{array}{c}\text { Group II } \\
(\mathrm{n}=45)\end{array}$ & P value \\
\hline 1-year GS & $96 \%$ & $93.3 \%$ & N.S. \\
\hline 1-year death censored GS & $100 \%$ & $95.6 \%$ & N.S. \\
\hline 1-year PS & $96 \%$ & $95.6 \%$ & N.S. \\
\hline 3-year GS & $92 \%$ & $93.3 \%$ & N.S. \\
\hline 3-year death censored GS & $100 \%$ & $95.6 \%$ & N.S. \\
\hline 3-year PS & $92 \%$ & $95.6 \%$ & N.S. \\
\hline
\end{tabular}

Abbreviations: GS $=$ Graft survival, $\mathrm{PS}=$ patient survival.

Complications. Three surgical complications (all in Group II) were diagnosed (P value $=$ N.S.). They consisted in: ureteral stenosis (1 patient), lymphocele (1 patient) and 1 hematoma.

Patient and graft outcome. Two patients in Group I died (1 patient from unknown cause at 9 months and 1 from Gastro-intestinal stroma tumor at 30 months after $\mathrm{KT}$ ) and 2 others died in Group II (both from pneumonia at 5 and 6 months after KT) (P value $=$ N.S). Post transplant malignancy occurred in 1 patient in Group I. The patient died at 30 months after KT. The 1 and 3 year GS and PS were similar in the 2 groups and are summarized in Table 7.

Financial Issues. Financial burdens are of concern in our transplant program. For low immunological risk patients, either ATG-F (as a single dose of $6 \mathrm{mg} / \mathrm{kg}$ ) or Basiliximab was used as induction therapy. This means that for an $80 \mathrm{~kg}$ recipient, $480 \mathrm{mg}$ of ATG-F (equivalent to 5 vials of $100 \mathrm{mg}$ each) should be given. Knowing that each vial costs 362 US\$, the treatment course is evaluated to $1810 \mathrm{US} \$$. As for the Basiliximab, 2 standard doses of $20 \mathrm{mg}$ were administered (regardless of the patient's weight), for a total cost of 3240 US\$. This constitutes 11 to $20 \%$ of the total hospital bill which represents a major concern for the third-party payer.

\section{Discussion}

Induction therapy using lymphocyte-depleting polyclonal antibodies or lymphocyte non-depleting monoclonal antibodies that inhibit the T-cell response is widely used in KT. It aims to avoid AR in KTRs, to provide an immunologic cover for patients suffering from DGF [21] and to improve both short and long-term outcomes [12]. However, Antibody induction is not without risk. Increased rates of infection have been reported with lymphocyte-depleting induction [22] arising from complex immunomodulatory effects on the host [23] which also increase the risk of malignancy on long term [24]. Lately, the introduction of IL2-RA instead of polyclonal antibodies becomes a common practice, mainly in patients with low immunological risk, because of their equivalent efficacy in the reduction of AR in addition to their safety profile as shown in several studies [25]. In USA, $90 \%$ of all kidney transplant recipients receive induction therapy, with $65 \%$ given lymphocyte-depleting agents and approximately $25 \%$ given a non-depleting IL2-RA [26]. Currently, the choice of induction therapy is based on the risk-benefit considerations for each patient.

The latest guidelines published in 2009 by KDIGO [1] (Kidney Disease: Improving Global Outcomes) recommend the use of a biologic agent as induction therapy in all KTRs. IL2-RA should be the first therapy (Grade IB) in patients with low immunological risk, and lymphocyte depleting agent for those at high immunologic risk (Grade 2B). This strategy is adopted by many transplant centers [27-31]. In 2010, Cochrane Collaboration made a meta-analysis of randomized control trials in low risk patients comparing patients receiving IL2-RA, Placebo or Thymoglobulin. When compared to Placebo, there was less biopsy proven acute rejection (BPAR) of $30 \%$ and less graft loss with IL2-RA. In addition, IL2-RA had similar effects to thymoglobulin with fewer adverse reactions which made the authors favor its use [32]. 
However, looking at the KDIGO criteria, the number of HLA mismatch is not specified as well as the level of PRA threshold which both categorize the immunological risk of the patients. Moreover, the Cochrane study included patients in the 1990's and early 2000 using maintenance immunosuppression that have been superseded. CyA-me (87\%), MMF (50\%), Azathioprine (28\%) and double therapy (22\%) were used. Presently, Tacro is more used [33], MMF is replacing Azathioprine [34] and triple immunosuppression is standardized keeping steroids [33]. This might explain the drop of the 1 -year AR rate from $50 \%$ in the early 1990 to $10-15 \%$ nowadays [35] questioning the need of induction therapy in KT. Only retrospective studies were published in the literature comparing the type of induction therapy. Gralla and Woseman [36] analyzed the data acquired from the US registry about primary KTRs operated between 2000 and 2008. They compared patients who were treated with Tacro, Mycofenolate acid (MPA) and prednisone with or without IL2-RA induction. Although the 1-year AR rate was reduced with IL2-RA induction (11.6\% versus $13 \%$ without induction), there was no improvement regarding GS and PS. Moreover, Willoughby et al [37] analyzed the outcomes of KTRs who were treated with either rabbit anti-thymocyte globulin (rATG), Basiliximab or no induction using multivariable statistical adjustments and case matching methods. No improvement was noticed between the 3 groups of patients regarding AR rate at 6 months (all were $<15 \%$ ), graft and patient survivals. Nevertheless, the composite triple end point of AR, GS and PS was statistically superior when rATG was administered in comparison to Basiliximab and both agents were superior to no induction. However, this real clinical benefit is questionable depending on the different statistically approaches used. In addition, KTRs from living donors operated between 2000 and 2012 and treated with Tacro, MPA and steroids were retrospectively reviewed by Tanriover et al [38]. The authors did not find any advantage in giving I12-RA induction regarding AR rate at 1 year $(11.7 \%$ versus $12.4 \%$ in no induction $)$ and 5 -year GS $(\mathrm{P}$ value $=\mathrm{NS})$. In a report from the Australia and New Zealand Dialysis and Transplant Registry (ANZDATA), the same findings were noticed in Tacro-treated KTRs with either low or intermediate immunological risk concerning the benefit of IL2-RA induction in reducing AR (RR 0.9, 95\% CI 0.68-1.2; $\mathrm{p}=0.48)$ [39].

Opelz et al [40] analyzed the data of 38311 first deceased-donor kidney transplants done between 2004 and 2013. Transplants were classified as 'normal risk' or 'increased risk' according to current guidelines. Patients were divided in 3 groups according to the type of induction therapy: IL2-RA $(\mathrm{n}=19 \quad 334 ; 50 \%)$, rATG $(\mathrm{n}=3 \quad 458 ; 9 \%)$ and no induction $(\mathrm{n}=15 \quad 519 ; 41 \%)$ knowing that rATG or IL-2RA induction was given to $64 \%$ of increased-risk and $53 \%$ of normal-risk patients, respectively. The use of rATG and IL2-RA induction in increased-risk patients significantly reduced the risk of $\mathrm{AR}$ and graft loss. However, no difference was found between the 3 groups, in low immunological risk patients regarding the graft loss rate as well as the censored graft loss, PS and AR incidence at 3 years. They concluded that induction therapy following KT should be targeted to increased-risk transplants. In this analysis, a beneficial effect of antibody induction in normal-risk transplants could not be demonstrated. Finally, OSAKA trial enrolling 1251 patients has shown the similar efficacy of the once-daily formulation of Tacro at 2 different doses $(0.2 \mathrm{mg} / \mathrm{kg} /$ day; Group I and $0.3 \mathrm{mg} / \mathrm{kg} /$ day; Group II $)$ in comparison to standard Tacro $(0.2 \mathrm{mg} / \mathrm{kg}$ twice daily; Group III). MPA and steroids were given to all the patients but without any induction. BPAR rates were not statistically different in the 3 groups $(12.7 \%, 16.1 \%$ and $10.3 \%$ respectively) at 24 weeks [41].

Bunnapradist et al state in a multivariate analysis that using antibody induction therapy to KTRs, having a graft from deceased donors, markedly reduced the rejection rate for all degrees of HLA mismatches except for 1 and 0 haplotype-mismatched group who did not show any significant difference [42].

On the opposite side, other studies comparing no induction to anti-thymocyte globulin (ATG), IL-2RA, and Alemtuzumab to KTRs from living donors, have produced different results. rATG appears to be safe and effective in KT from living donors $[43,44,45]$. This was also shown in a single-center study in which, compared with a national control group with no induction, rATG use provided superior 5-year PS $(96 \%$ versus $90 \%, \mathrm{P}$ value $=0.0326)$, GS (82 versus. 79\%, P value $=0.0901)$, and 1 -year AR rate $(2 \%$ versus $21 \%, \mathrm{P}$ value $<0.001)$ [46]. Another trial at a single institution showed that using $\mathrm{rATG}$ in KT from living unrelated donors, was associated with a significant reduction of $\mathrm{AR}$ rates $(2 \%$ versus $48 \%$, P value $<0.001$ ) in the first post-transplant year in comparison to no induction [47]. A report from the Australian/New Zealand registry has shown similar results when IL-2RA was used in comparison to no induction. The occurrence of AR was reduced to $51 \%(\mathrm{P}<0.001)$ as well as the overall graft loss $(\mathrm{HR}=0.58,95 \% \mathrm{CI}: 0.35-0.96 ; \mathrm{P}$ value $=0.03)[48]$.

In our study, the benefit of using induction therapy in low risk, half-haplotype match KTRs from living donors was raised. We have shown that induction therapy did not induce any improvement in AR rate and severity, identified by the need for ATG-F, as well as the 1 year GS and PS. This might be explained by the use of Tacrolimus more frequently in the group without induction.

In hospital infections rate and type were not different between the 2 groups. This might be related to adequate pre transplant preparation and post-transplant prophylaxis regimens adopted. However, patients who did not receive induction therapy, had less overall infections which include both in hospital and out of hospital infections till 1 year after KT. As for the CMV infections, the use of induction therapy did not have any effect on the occurrence of CMV disease, type and timing, knowing that more patients in the non-induction group did receive any anti-CMV prophylaxis.. This is in contradiction to what many studies have stated that patients who received ATG therapy are at higher risk to develop infectious complications such as CMV.

Many studies have shown that there is an additive impact of AR and DGF on long-term graft outcomes. Therefore, by giving ATG to KTRs who are suffering from DGF, the negative impact of AR will be minimized threw its prevention. In our study, we found that the hospital stay duration and the incidence of DGF were not 
different between the 2 groups with no impact of DGF on $\mathrm{AR}$ rate and GS as well. Our results are in concordance with those of Chapal et al [21] who have questioned the benefit of using ATG in low immunological risk patients. They evaluated its risk/benefit ratio and the consequences of a possible reduction in DGF incidence, against side effects related to such depleting induction therapy. The idea was to reduce excessive unjustified ATG prescription, which is associated with serious adverse events such as, fever, serum sickness, infectious disease or PTLD.

The administration of induction therapy did not have any protective effect on the kidney graft. This was demonstrated by the similarity of the kidney function at 3 years after KT.

Concerning the hematological problems, there was a greater drop in hemoglobin and platelets blood levels in the patients who received induction immunosuppressive therapy as well as a higher need of packed red blood cells transfusions, mostly related to the administration of ATG in this particular group of patients. This appears in correlation with what it is mentioned in the literature that anemia limits the delivery of oxygen to tissues, particularly to the tubulo-interstitium, therefore accelerating the decline in renal function. This effect is increased by a further insult to the kidney threw the creation of reactive oxygen radicals secondary to the hypoxic state which can be potentiated by the use of immunosuppressive agents. These findings are consistent with a prospective cohort study by Molnar et al [49] who found that baseline anemia significantly predicted patient's mortality and graft failure over 4 year of follow-up. Two other studies that also demonstrated that post transplantation anemia at 1 year was associated with decreased GS and higher patient's mortality. In our study we have demonstrated that giving induction therapy to low immunological risk half haplotype KTRs, did not have any positive effect on GS, graft function and patient survival. Moreover, induction therapy, most probably ATG, resulted in more anemia and thrombocytopenia as well as increased incidence of 3-years bacterial infections rate.

\section{Conclusion}

In summary, the use of IL2-RA or ATG in low-immunological risk KTRs under Tacrolimus, MPA and steroids regimen is not beneficial in terms of decreasing AR occurrence and/or improving both graft and patient survival [36-39,41,50,51]. Moreover, the financial burden as well as the increased risks of induction therapy, including a possible increase in infectious and malignant complications [52-57] should be taken into consideration. However, these concerns are declining based on recent studies in which rATG dosing was lower than in the past $[58,59,60,61,62]$. In addition, the high cost of immunosuppression regimens imposes a financial burden on the health system and the patients as well. It is then crucial to identify a subgroup of KTRs in whom we could generate cost savings without compromising patient and graft safety [63]. Therefore, the European Renal Best Practice (ERBP) initiative has proposed a somewhat more cautious approach, concluding that the cost of IL-2RA induction may not be justified in patients receiving Tacro and MPA [64]. Consequently, antibody induction therapy should be targeted to increased-risk patients.

\section{List of Abbreviations}

AR: acute rejection

ATG: anti-thymocyte globulin

ATG-F: anti-thymocyte globulin-Fresenius

BPAR: biopsy proven acute rejection

CMV: cytomegalovirus

CNIs: calcineurin inhibitors

CyA-me: cyclosporine microemulsion

DGF: delayed graft function

DSA: donor-specific antibodies

EBV: epstein-Barr virus

eGFR: estimated glomerular filtration rate

GS: graft survival

HLA: human leukocyte antigens

HSV: herpes simplex virus

IL2-RA: interleukin 2 receptor antagonists

KDIGO: Kidney Disease: Improving Global Outcomes

KT: kidney transplantation

KTRs: kidney transplant recipients

MMF: mycofenolate mofetil

MPA: mycofenolate acid

$\mathrm{N}=$ neoral

rATG: rabbit anti-thymocyte globulin

SGF: slow graft function

Tacro: tacrolimus

PCR: polymerase chain reactive

PRA: panel reactive antibody

PS: patient survival

\section{References}

[1] Kidney Disease: Improving Global Outcomes (KDIGO) Transplant Work Group. KDIGO clinical practice guideline for the care of kidney transplant recipients. American Journal of Transplantation 2009; 9(Suppl 3): S1-S157.

[2] Marcen R. Immunosuppression and renal transplant rejection: review of current and emerging therapies. Clin Invest 2011 1(6), 859-877.

[3] Hardinger KL, Brennan DC, Klein CL. Selection of induction therapy in kidney transplantation. Transpl Int 2013; 26: 662-672.

[4] Butler T, Hayde N. Impact of induction therapy on Delayed Graft Function Following Kidney transplantation in Mated Kidneys. Transplant Proc. 2017 Oct;49(8):1739-1742.

[5] Ekberg H, Tedesco-Silva H, Demirbas A et al. for the ELITESymphony Study. Reduced Exposure to Calcineurin Inhibitors in Renal Transplantation. N Engl J Med 2007; December 20; 357: 2562-2575.

[6] Dharnidharka VR, Naik AS, Axelrod et al. Center practice drives variation in choice of US kidney transplant induction therapy: a retrospective analysis of contemporary practice. Transpl Int. 2018 Feb; 31(2): 198-211.

[7] Grenda R. Biologics in renal transplantation. Pediatr Nephrol 2015; 30: 1087-1098.

[8] Ramirez C.B., Marino I.R. The role of basiliximab induction therapy in organ transplantation. Expert Opin. Biol. Ther. 2007; 7 : 137-148.

[9] Novartis Pharmaceutical Corporation Simulect ${ }^{\circledR}$ (basiliximab): Summary of product characteristics. [(accessed on 11 November 2013)]. Available online: www.pharma.us.novartis.com.

[10] Mottershead M., Neuberger J. Daclizumab. Expert Opin. Biol. Ther. 2007; 7: 1583-1596. 
[11] Deeks E.D., Keating G.M. Rabbit antithymocyte globulin (thymoglobulin): A review of its use in the prevention and treatment of acute renal allograft rejection. Drugs. 2009; 69: 1483-1512.

[12] Wagner SJ and Brennan DC. Induction therapy in renal transplant recipients: How convincing is the current evidence? Drugs 2012; 72(5), pp. 671-683.

[13] Kaisike B.L., Kukla A, Thomas D et al. Lymphoprolifertaive disorders after adult kidney transplant: epidemiology and comparison of registry report with claims-based diagnoses. Am J Kidney Dis, 58 (2011), pp 971-980.

[14] Razonable RR. Strategies for managing cytomegalovirus in transplant recipients. Expert Opin Pharmacother. 2010; 11: 1983-1997.

[15] F. Luan FL. Six-month low-dose valganciclovir prophylaxis in cytomegalovirus $\mathrm{D}+\mathrm{R}$ - kidney transplant patients receiving thymoglobulin induction. Transplant Proc. 2013; 45: 175-177.

[16] Requião-Moura LR, Ferraz E, Matos AC et al. Comparison of long-term effect of thymoglobulin treatment in patients with a high risk of delayed graft function. Transplant Proc. 2012; 44: 2428-2433.

[17] Shanfield, I. (1972). New experimental methods for implantation of ureter in bladder and conduit. Transplant. Proc. 4, 637.

[18] Padiyar A, Akoum FH, Hricik DE. Management of the kidney transplant recipient. Prim Care 2008; 35: 433-506.

[19] Maki DG, Weise CE, Sarafin HW. A semi-quantitative culture method for identifying intravenous-catheter-related infection. N Engl J Med 1977; 296: 1305-9.

[20] Solez K et al. Banff 07 classification of renal allograft pathology: updates and future directions. Am J Transplant. 2008 Apr; 8(4): 753-60.

[21] Chapal M, Foucher Y, Marguerite $M$ et al. PREventing Delayed Graft Function by Driving Immunosuppressive InduCtion Treatment (PREDICT-DGF): study protocol for a randomized controlled trial. Trials. 2015; 16: 282.

[22] Padiyar A, Augustine JJ, Hricik DE. Induction antibody therapy in kidney transplantation. Am J Kidney Dis 2009; 54: 935-944.

[23] Mohty M. Mechanisms of action of antithymocyte globulin: T-cell depletion and beyond. Leukemia 2007; 21: 1387-1394.

[24] Mohty M, Bacigalupo A, Saliba F et al. New directions for

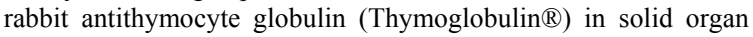
transplants, stem cell transplants and autoimmunity. Drugs 2014; 74: 1605-1634.

[25] Bumgardner GL, Hardie I, Johnson RW et al. Phase III Daclizumab Study Group. Results of 3-year phase III clinical trials with daclizumab prophylaxis for prevention of acute rejection after renal transplantation. Transplantation. 2001; 72: 839-845.

[26] Saran R, Li Y, Robinson B et al. US Renal Data System 2014 Annual Data Report: Epidemiology of Kidney Disease in the United States. Am J Kidney Dis 2015; 65(6 Suppl 1): A7.

[27] Brennan DC, Daller JA, Lake KD et al. Rabbit antithymocyte globulin versus basiliximab in renal transplantation. $\mathrm{N}$ Engl J Med 2006; 355: 1967-1977

[28] Noel C, Abramowicz D, Durand D et al. Daclizumab versus antithymocyte globulin in high-immunological-risk renal transplant recipients. J Am Soc Nephrol 2009; 20: 1385-1392.

[29] Wagner SJ, Brennan DC. Induction therapy in renal transplant recipients: how convincing is the current evidence? Drugs 2012; 72: 671-683.

[30] Heemann U, Abramowicz D, Spasovski G et al. Endorsement of the Kidney Disease Improving Global Outcomes (KDIGO) guidelines on kidney transplantation: a European Renal Best Practice (ERBP) position statement. Nephrol Dial Transplant 2011; 26: 2099-2106.

[31] Kidney Disease: Improving Global Outcomes Transplant Work Group. KDIGO clinical practice guideline for the care of kidney transplant recipients. Am J Transplant 2009; 9(Suppl 3): S1-S155.

[32] Webster AC, Ruster LP, Mc Gee R et al. Interleukin 2 receptor antagonists for kidney transplant recipients. Cochrane Database Syst Rev 2010; CD003897.

[33] OPTN/SRTR Annual Report 2012. http://srtr.transplant.hrsa.gov/annual_reports/2012/pdf/2012_SRT R_ADR.pdf.

[34] Ekberg H, Tedesco-Siva H, Demirbas A et al. ELITE-Symphony Study. Reduced exposure to calcineurin inhibitors in renal transplantation. N Engl J Med 2007; 357: 2562-2575.
[35] Meier-Kriesche HU, Schold JD, Srinivas TR et al. Lack of improvement in renal allograft survival despite a marked decrease in acute rejection rates over the most recent era. Am J Transplant 2004; 4: 378-383.

[36] Gralla J, Wiseman AC. The impact of IL2-RA induction therapy in kidney transplantation using tacrolimus and mycophenolate based immunsuppression. Transplantation 2010; 90: 639-644.

[37] Willoughby LM, Schnitzler MA, Brennan DC et al. early outcomes of thymoglobulin and basiliximab induction in kidney trasnplantation: Application of statistical approaches to reduce bias in observational comparisons. Transplantation 2009; 87: 1520-1529.

[38] Tanriover B, Zhang S, MacConmara M et al. Induction therapies in live donor kidney transplantation on tacrolimus and mycophenolate with or without steroid maintenance. Clin J Am Soc Nephol 2015; 10:1041-1049.

[39] Lim WH, Chadban SJ, Campbell S et al. Interleukin-2 receptor antibody does not reduce rejection risk in low immunological risk or tacrolimus-treated intermediate immunological risk renal transplant recipients. Nephrology 2010; 15: 368-376.

[40] Opelz G, Unterrainer C, Susal C et al. Efficacy and safety of antibody induction therapy in the current era of kidney transplantation. Nephrol Dial Transplant. 2016; 31(10): 1730-1738

[41] Albano L, Banas B, Klempnauer JL et al. Optimizing immunosuppression after kidney transplantation with ADVAGRAF study group. OSAKA trial: A randomized, controlled trial comparing tacolimus $\mathrm{OD}$ and $\mathrm{BD}$ in kidney transplantation. Transplantation 2013; 96: 897-903.

[42] Bunnapradist S, Hong A, Lee B et al. Multivariate analysis of the effectiveness of using antibody induction therapy according to the degree of HLA mismatches. Transplant Proc. 2005; 37(2): 886-888.

[43] Hardinger KL, Schnitzler MA, Koch MJ et al. Thymoglobulin induction is safe and effective in live-donor renal transplantation: a single center experience. Transplantation 2006; 81: 1285.

[44] Miller JT, Collins CD, Stuckey LJ et al. Clinical and economic outcomes of rabbit antithymocyte globulin induction in adults who received kidney transplants from living unrelated donors and received cyclosporine-based immunosuppression. Pharmacotherapy 2009; 29: 1166.

[45] Schenker P, Ozturk A, Vonend O et al. Single-dose thymoglobulin induction in living-donor renal transplantation. Ann Transplant 2011; 16: 50 .

[46] Hardinger KL, Schnitzler MA, Koch MJ et al. Thymoglobulin induction is safe and effective in live-donor renal transplantation: a single center experience. Transplantation 2006; 81: 1285].

[47] Miller JT, Collins CD, Stuckey LJ et al. Clinical and economic outcomes of rabbit antithymocyte globulin induction in adults who received kidney transplants from living unrelated donors and received cyclosporine-based immunosuppression. Pharmacotherapy 2009; 29: 1166].

[48] Lim WH, Chang SH, Chadban SJ et al. Interleukin-2 receptor antibody reduces rejection rates and graft loss in live-donor kidney transplant recipients. Transplantation 2009; 88: 1208].

[49] Molnar MZ, Czira M, Ambrus C et al. Anemia is associated with mortality in kidney transplanted patients: A prospective cohort study. Am J Transplant 2007; 7: 818-824.

[50] Hellemans R, Bosmans JL and Abramowicz D. Induction therapy for kidney transplant recipients: Do we still need Anti-IL2 receptor monoclonal antibodies?. Am J Transplant 2016; 10: 1-6.

[51] Rostaing L, Charpentier B, Glyda M et al. Alefacept combined with tacrolimus, mycophenolate mofetil and steroids in de novo kidney transplantation: A randomized controlled trial. Am J Transplant 2013; 13: 1724-1733.

[52] Webster AC, Ruster LP, McGee R et al. Interleukin 2 receptor antagonists for kidney transplant recipients. Cochrane Database Syst Rev 2010; CD003897.

[53] Mourad G, Garrigue V, Squifflet JP et al. Induction versus noninduction in renal transplant recipients with tacrolimus-based immunosuppression. Transplantation 2001; 72: 1050-1055.

[54] Charpentier B, Rostaing L, Berthoux F et al. A three-arm study comparing immediate tacrolimus therapy with antithymocyte globulin induction therapy followed by tacrolimus or cyclosporine A in adult renal transplant recipients. Transplantation 2003; 75: 844-851.

[55] Owers DS, Webster AC, Strippoli GF et al. Pre-emptive treatment for cytomegalovirus viraemia to prevent cytomegalovirus disease 
in solid organ transplant recipients. Cochrane Database Syst Rev2013; 2: CD005133.

[56] Opelz G, Naujokat C, Daniel V et al. Disassociation between risk of graft loss and risk of non-Hodgkin lymphoma with induction agents in renal transplant recipients. Transplantation 2006; 81: 1227-1233.

[57] Kirk AD, Cherikh WS, Ring M et al. Dissociation of depletional induction and posttransplant lymphoproliferative disease in kidney recipients treated with alemtuzumab. Am J Transplant 2007; 7: 2619-2625.

[58] Hertig A, Zuckermann A. Rabbit antithymocyte globulin induction and risk of post-transplant lymphoproliferative disease in adult and pediatric solid organ transplantation: An update. Transpl Immunol2015; 32: 179-187.

[59] Caillard S, Lamy FX, Quelen C et al. French Transplant Centers. Epidemiology of posttransplant lymphoproliferative disorders in adult kidney and kidney pancreas recipients: Report of the French registry and analysis of subgroups of lymphomas. Am J Transplant 2012; 12: 682-693.
[60] Hall EC, Engels EA, Pfeiffer RM et al. Association of antibody induction immunosuppression with cancer after kidney transplantation. Transplantation 2015; 99: 1051-1057.

[61] Marks WH, Ilsley JN, Dharnidharka VR. Posttransplantation lymphoproliferative disorder in kidney and heart transplant recipients receiving Thymoglobulin: A systematic review. Transplant Proc 2011; 43: 1395-1404

[62] Bustami RT, Ojo AO, Wolfe RA et al. Immunosuppression and the risk of post-transplant malignancy among cadaveric first kidney transplant recipients. Am J Transplant 2004; 4: 87-93.

[63] Erickson KF, Winkelmayer WC, Busque S et al. A Cost Analysis of Tolerance Induction for Two-Haplotype Match Kidney Transplant Recipients. American Journal of Transplantation 2016; 16: 371-373.

[64] Heemann U, Abramowicz D, Spasovski G et al. Endorsement of the Kidney Disease Improving Global Outcomes (KDIGO) guidelines on kidney transplantation: a European Renal Best Practice (ERBP) position statement. Nephrol Dial Transplant 2011; 26: 2099-2106.

(C) The Author(s) 2019. This article is an open access article distributed under the terms and conditions of the Creative Commons Attribution (CC BY) license (http://creativecommons.org/licenses/by/4.0/). 